\title{
THE COMPRESSIVE STRENGTH DEVELOPMENT OF MAGNESIUM OXYCHLORIDE CEMENT COMPRISING A COMPOSITE ADDITIVE IN BRINE
}

\author{
QING HUANG*,**,***, YING LI*,**, CHENGGONG CHANG*,**, WEIXIN ZHENG*,**, JING WEN*,**, \\ JINMEI DONG ${ }^{*} * *$, YANGYANG MAN $* * *, * * *$, DANCHUN A $* * *, * * *,{ }^{*}$ XUEYING XIAO ${ }^{*}, * *,{ }^{*}$ YUAN ZHOU*, ** \\ *Key Laboratory of Comprehensive and Highly Efficient Utilization of Salt Lake Resources, Qinghai Institute of Salt Lakes, \\ Chinese Academy of Sciences, Xining, 810008, China \\ **Key Laboratory of Salt Lake Resources Chemistry of Qinghai Province, \\ Xining, 810008, China \\ ***University of Chinese Academy of Sciences, \\ Beijing, 100049, China \\ "E-mail: xiaoxy@isl.an.cn; zhouy@isl.ac.cn
}

Submitted March 21, 2019; accepted April 27, 2019

\begin{abstract}
Keywords: Magnesium oxychloride cement, Anti-corrosion additive Q101, Compressive strength development, Compressive strength retention, Optimum dosage, Brine environment

In this paper, the performance of magnesium oxychloride cement (MOC) in brine environment after the addition of an anticorrosion admixture (Q101) was investigated. The compressive strength, compressive strength retention, crystal composition and microstructure were analysed in detail. The results show that the compressive strength of the MOC with the Q101 admixture maintains a high compressive strength of more than $100 \mathrm{MPa}$ in air, and decreases slightly in the raw brine and the aging brine, but the decreases are not significant with the compressive strength of $80 \mathrm{MPa}$. This demonstrates the excellent salt brine resistance in brine environment of the MOC. One reason is that the high content of $\mathrm{Mg}^{2+}$ and $\mathrm{Cl}^{-}$in brine suppress the dissolution rate of main hydration product in the MOC. The other is the addition of an anti-corrosion additive that improves the salt brine resistance by about $30 \%$. However, the compressive strength and strength retention of the MOC after the raw brine immersion are higher than the aging brine immersion. The reason may be that the salts fill the surface and the pores in the samples that prevented water erosion to some extent. Meanwhile, the MOC pastes have the biggest compressive strength retention when the Q101 was up to $10 \%$ over the long run. As a result, the optimum dosage of Q101 is $10 \%$ in this experiment.
\end{abstract}

\section{INTRODUCTION}

Magnesium oxychloride cement(MOC), also known as Sorel cement or magnesia cement, is a kind of pneumatic cementitious material invented by the French scientist Sorel in 1867. It is formed by mixing a certain concentration of magnesium chloride solution with light-burned magnesia powder. At room temperature, its hydration products are mainly $5 \mathrm{Mg}(\mathrm{OH})_{2} \cdot \mathrm{MgCl}_{2} \cdot 8 \mathrm{H}_{2} \mathrm{O}$ (5.1.8 phase), $3 \mathrm{Mg}(\mathrm{OH})_{2} \cdot \mathrm{MgCl}_{2} \cdot 8 \mathrm{H}_{2} \mathrm{O}(3 \cdot 1 \cdot 8$ phase) and $\mathrm{Mg}(\mathrm{OH})_{2}$ [1-7] as shown in the following Equations 1, 2 and 3. These hydration products are cross-connected to form a crystal network structure [8]. Among them, the $5 \cdot 1.8$ phase and $3 \cdot 1 \cdot 8$ phase are responsible for the excellent mechanical properties of MOC. Compared with ordinary Portland cement (OPC), MOC has many attractive characteristics, such as early high strength, light weight, low alkalinity, wood substitutes and heat insulation, which have attracted widespread attention all over the world [9-11].

$$
\begin{aligned}
& 5 \mathrm{MgO}+\mathrm{MgCl}_{2}+13 \mathrm{H}_{2} \mathrm{O}= \\
& =5 \mathrm{Mg}(\mathrm{OH})_{2} \cdot \mathrm{MgCl}_{2} \cdot 8 \mathrm{H}_{2} \mathrm{O}(5 \cdot 1 \cdot 8 \text { phase }) \\
& 3 \mathrm{MgO}+\mathrm{MgCl}_{2}+11 \mathrm{H}_{2} \mathrm{O}= \\
& =3 \mathrm{Mg}(\mathrm{OH})_{2} \cdot \mathrm{MgCl}_{2} \cdot 8 \mathrm{H}_{2} \mathrm{O}(3 \cdot 1 \cdot 8 \text { phase }) \\
& \mathrm{MgO}+\mathrm{H}_{2} \mathrm{O}=\mathrm{Mg}(\mathrm{OH})_{2}
\end{aligned}
$$

There are a large number of salt lakes distributed in the north-western part of China, which are surrounded by a large area of super-salt soil. This kind of hypersaline soil with high salt content causes severe corrosion to concrete and poses a serious threat to the durability of concrete and reinforced concrete structures [12]. There are also large areas of salt lakes in other parts of the world, such as the Great Salt Lake in the United States, Elton Lake in Russia, the Dead Sea and so on. These areas also have the problem with corrosion of OPC concrete by saline soil. Therefore, it is urgent to develop new types of cementitious materials with durability and high bearing capacity for the application in saline soil 
areas. Research reported [13] that MOC itself contains halogen components, so it has natural resistance to salt and halogen corrosion.

However, the existing research results agree that MOC is a kind of gas-hardening cementitious material, which means that it cannot maintain strength in water and a humid environment. Therefore, it cannot be used in soils below the groundwater level or in a humid state [14]. When the hardened MOC is immersed in water or humid environment, the $5 \cdot 1 \cdot 8$ phase and $3 \cdot 1 \cdot 8$ phase are transformed into a $\mathrm{Mg}(\mathrm{OH})_{2}$ phase without gelatinisation, and then it eventually loses strength [15-17].

Therefore, it is necessary to mix anti-corrosion modifiers to improve the application value of MOC in saline soil areas with high salinity. Taking the abovementioned factor into account, this paper is dedicated to adding different dosages of the anti-corrosion admixture Q101 to try to find the optimum dosage in MOC in a high salinity environment, and aim to apply the anticorrosion admixture to improving the salt and halogen corrosion resistance of MOC.

\section{EXPERIMENTAL}

Raw materials

The light-burned magnesium oxide powder used in this experiment was produced from Haicheng, Liaoning, China. The active magnesium oxide (MgOa) content is $64.30 \%$ according to the required direct hydration in YB/T 4019-2006. The phase composition of the powder was analysed by X-ray diffraction (XRD). The results are shown in Figure 1. The main chemical composition of the powder was analysed by X-ray fluorescence (XRF) as shown in Table 1. The main chemical composition of the light-burned magnesium oxide powder used in the experiment was $\mathrm{MgO}$ with a content of $85.96 \%$ and there are small amounts of $\mathrm{SiO}_{2}, \mathrm{CaO}, \mathrm{Al}_{2} \mathrm{O}_{3}$ and $\mathrm{Fe}_{2} \mathrm{O}_{3}$. The chemical composition of the light burnt magnesia analysed by XRF is basically consistent with the phase composition of the XRD analysis.

The bischofite used in this experiment was an industrial white crystal produced in Golmud, Qinghai Province, China. The main chemical composition of the bis-chofite was analysed by inductively coupled plasma atomic emission spectrometry (ICP-AES) as shown in Table 2. The content of $\mathrm{MgCl}_{2}$ in the bischofite is $46.43 \%$. The impurity contents of $\mathrm{KCl}, \mathrm{NaCl}, \mathrm{CaCl}_{2}$ and $\mathrm{MgSO}_{4}$ are $0.21 \%, 0.36 \%, 0.01 \%$ and $0.02 \%$, respectively. The product meets the requirements for bischofite in WB/T 1018-2002.

The water used in this study is ordinary drinking freshwater, which is used for mixing the MOC specimens.

Two kinds of brines used in this study are aging brine and raw brine, which are used for immersing the MOC specimens. The aging brine and raw brine are taken from Chaerhan Salt Lake, Qinghai Province. The difference between the aging brine and the raw brine

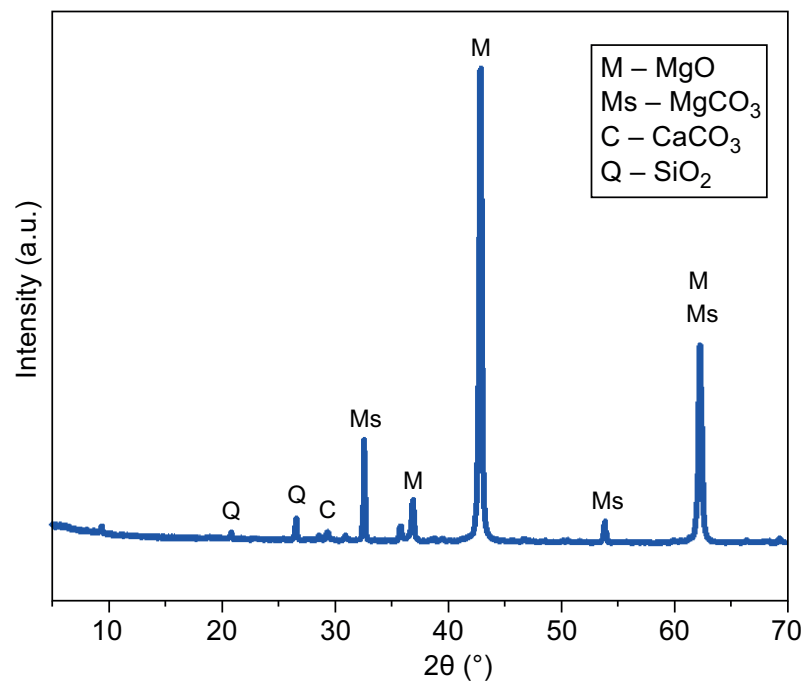

Figure 1. The XRD pattern of the magnesia.

Table 1. The chemical composition of the magnesia.

\begin{tabular}{lccccccc}
\hline Chemical constitution & $\mathrm{MgO}$ & $\mathrm{MgOa}$ & $\mathrm{CaO}$ & $\mathrm{Al}_{2} \mathrm{O}_{3}$ & $\mathrm{SiO}_{2}$ & $\mathrm{Fe}_{2} \mathrm{O}_{3}$ & $\mathrm{LOI}^{*}$ \\
\hline Content $(\%)$ & 85.96 & 64.30 & 1.29 & 1.28 & 6.03 & 0.57 & 4.87 \\
\hline
\end{tabular}

* Loss on ignition

Table 2. The chemical composition of the bischofite.

\begin{tabular}{lcccccc}
\hline Constitution & $\mathrm{MgCl}_{2}$ & $\mathrm{KCl}$ & $\mathrm{NaCl}$ & $\mathrm{CaCl}_{2}$ & $\mathrm{MgSO}_{4}$ & Water insoluble \\
\hline Content (\%) & 46.43 & 0.21 & 0.36 & 0.01 & 0.02 & 0.07 \\
\hline
\end{tabular}

Table 3. The chemical composition of the two types of leaching liquor $\left(\mathrm{g} \cdot \mathrm{l}^{-1}\right)$

\begin{tabular}{lccccccccc}
\hline Constitution & $\mathrm{K}^{+}$ & $\mathrm{Na}^{+}$ & $\mathrm{Ca}^{2+}$ & $\mathrm{Mg}^{2+}$ & $\mathrm{Fe}^{2+} / \mathrm{Fe}^{3+}$ & $\mathrm{Al}^{3+}$ & $\mathrm{SO}_{4}^{2-}$ & $\mathrm{HCO}_{3}^{-}$ & $\mathrm{Cl}^{-}$ \\
\hline Aging brine & 0.621 & 1.990 & 4.853 & 112.996 & 0.007 & 0.012 & 0.650 & 1.916 & 342.880 \\
Raw brine & 13.010 & 16.950 & 10.549 & 65.903 & 0.003 & 0.009 & 0.911 & 0.711 & 249.805 \\
\hline
\end{tabular}


is that the aging brine is the solution that extracts $\mathrm{KCl}$ from the raw brine. The composition of the aging brine and the raw brine is measured by ion chromatography (ICS) and ICP-AES as shown in Table 3.

\section{Specimen preparation}

In this experiment, the molar ratio of the fixed MOC to $\mathrm{MgOa} / \mathrm{MgCl}_{2} / \mathrm{H}_{2} \mathrm{O}$ is $7: 1: 15$ according to references $[10,18-20]$. Meanwhile, $0 \%, 5 \%, 10 \%$ and $15 \%$ of the compound admixture Q101 are added to prepare a homogeneous slurry. The samples of $20 \mathrm{~mm} \times 20 \mathrm{~mm}$ $\times 20 \mathrm{~mm}$ were cast in a steel mould and numbered P1, H5, H10 and H15, respectively. The samples were then demoulded after 24 hours natural curing at room temperature, and then cured at room temperature for 28 days. After that, some specimens were immersed in two kinds of leaching solutions for 3 days, 7 days, 14 days, 21 days and 28 days, while the others were naturally cured at room temperature to the same age.

The specimens were cured and immersed to the specified age, and their compressive strengths were measured. The strength retention was used to evaluate the salt brine resistance by comparing the compressive strength of the MOC before the brine immersion for 28 days and after immersion for the fixed time. The identification of crystalline phase of the samples was characterised by X-ray diffraction (XRD). The mineralogy and microstructure were studied by using scanning electron microscopy (SEM).

\section{RESULTS AND DISCUSSION}

Development of
the compressive strength

Figure 2 shows the development of the compressive strength in the MOC with different proportions of additive after being cured in air, immersed in the raw brine and the aging brine for 28 days. It can be seen from Figure 2 that the variation of the compressive strength of the mixed admixture MOC specimens in air, the raw brine and the aging brine is similar, and fluctuates within a certain intensity range. Figure 2 a shows that although the compressive strength of the MOC specimens with four different proportions of additive fluctuates up and down, their compressive strengths are not lower than $100 \mathrm{MPa}$. From Figure 2, it is apparent that after 28 days immersion in the raw brine and aging brine, the upper and lower fluctuations of the compressive strength in the MOC specimens increase and the compressive strength decreases slightly with the increasing immersion time, but they all maintained strength above $80 \mathrm{MPa}$. The result indicates the brilliant salt brine resistance of the MOC specimens. Figure 2 show that the changes to the compressive strength in the four different mixed additive MOC specimens are quite similar. Therefore, the optimum amount of the composite additive cannot be obtained at this time. However, it was found that the compressive strength of MOC in the aging brine and the raw brine maintained well, and it indicates that MOC has good corrosion resistance to salt brine.

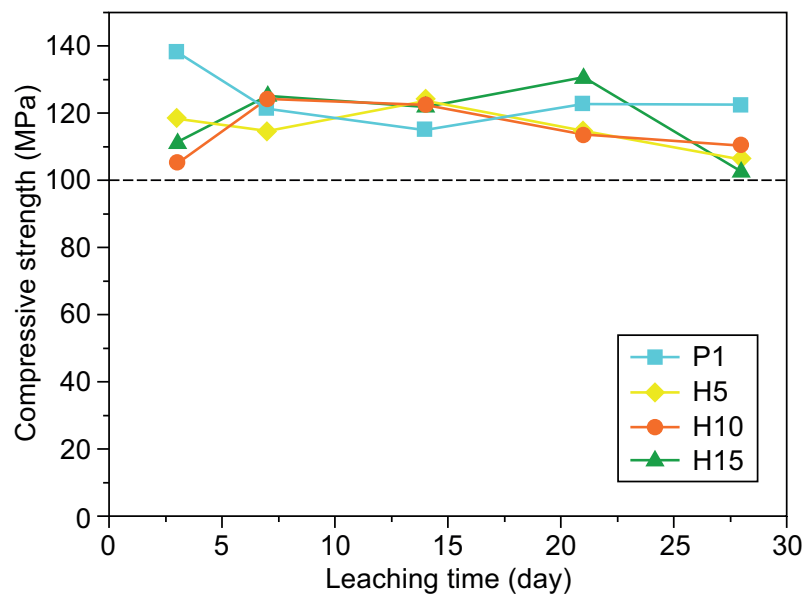

a) air curing

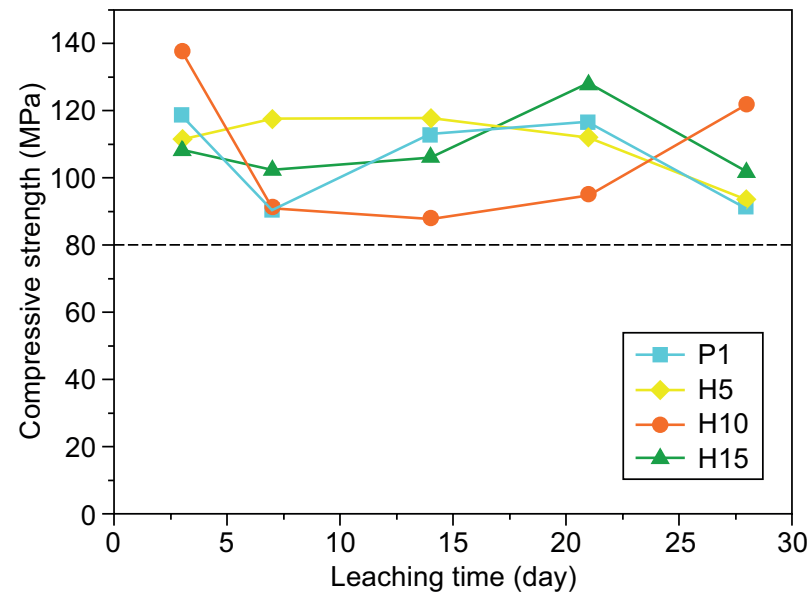

b) raw brine immersion

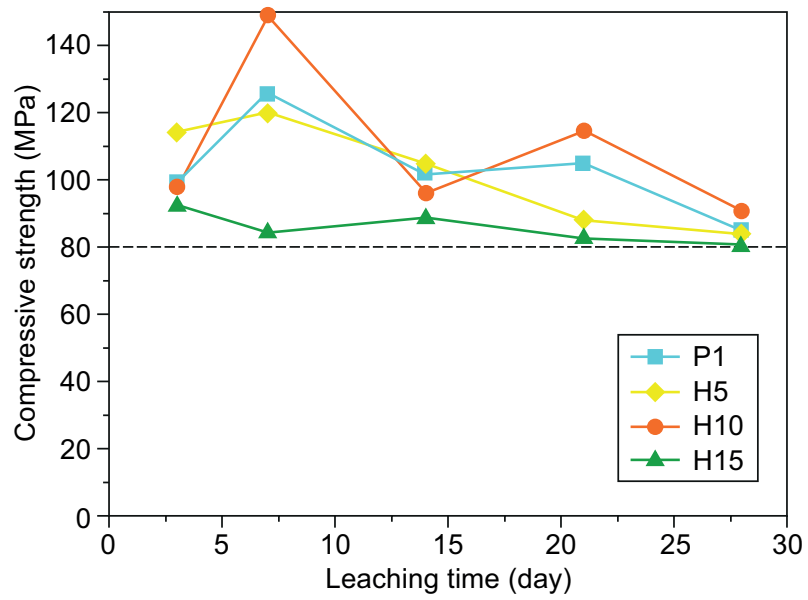

c) aging brine immersion

Figure 2. The compressive strength development of the MOC pastes cured in air, immersed in the raw brine and the aging brine. 
Compressive strength retention

Figure 3 shows the compressive strength retention curves of the MOC with different dosages of the additive soaked in the raw brine and aging brine for 28 days. From Figure 3a, it can be seen that the strength retention of the MOC specimens soaked in the raw brine has better salt brine resistance after the addition of Q101 than the neat P1 MOC paste for the immersion time (28 days). For example, the strength retentions of the $\mathrm{P} 1 \mathrm{MOC}$ are all lower than $100 \%$ in the immersion time and even when immersed for only 3 days. When immersed in the raw brine for less than 21 days, we can clearly find that the H5 sample has a higher strength retention than $100 \%$. This demonstrates that the appropriate dosage of the Q101 additive is $5 \%$ for the MOC pastes immersed in the raw brine for less than 21 days. Nevertheless, it is clear that the strength retention is higher than $100 \%$ in $\mathrm{H} 10$, while the other three samples are all lower than $100 \%$ after 28 -days in the raw brine immersion. Thus, we can conclude that $10 \%$ of the additive is beneficial for the MOC being immersed for a longer time in the raw brine.

The compressive strength retention of the MOC pastes immersed in the aging brine is exhibited in Figure $3 \mathrm{~b}$. It is evident that the strength retention of the MOC pastes steadily decreased when the immersing time increased. When immersed for less than 21 days in the aging brine, the H5 sample shows the highest strength retention among the other three samples. For instance, the strength retention of H5 is $98.9 \%$ while the strength retentions of $\mathrm{P} 1, \mathrm{H} 10$ and $\mathrm{H} 15$ are $83.0 \%$, $87.0 \%$ and $86.6 \%$, respectively. However, it is the same with the raw brine immersion where the H10 sample has the highest strength retention for being immersed for a longer time in the aging brine when compared to the other three samples. When immersed in the ageing brine for 21-days, the strength retention of H10 is $104.1 \%$, which is 1.21 times, 1.26 times, and 1.37 times higher

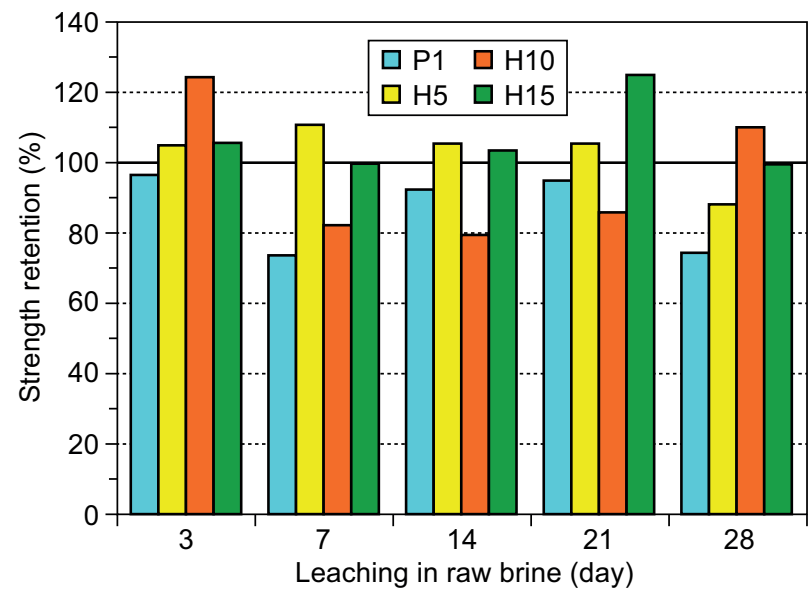

a) than $\mathrm{P} 1, \mathrm{H} 5$ and $\mathrm{H} 15$, respectively. As a result, the optimum dosage of the composite admixture is $10 \%$ in the brine environment over the long run.

It has been reported that MOC has poor water resistance after water immersion and the strength retention is lower than $20 \%$ when immersed in water for 28 days [21]. It is due to the predominant hydration products in MOC, such as the 5.1 .8 phase and 3.1 .8 phase, are unstable in water and gradually decompose to $\mathrm{Mg}(\mathrm{OH})_{2}$ and other soluble ions, thus, leading to the significant decrease in the compressive strength [9], as shown in Equation 4 and 5. On the contrary, when immersed in the raw brine and aging brine, the leaching liquor is abundant with $\mathrm{Mg}^{2+}$ and $\mathrm{Cl}^{-}$, that supplied lavish $\mathrm{Mg}^{2+}$ and $\mathrm{Cl}^{-}$and then suppresses the dissolution rate of the main hydration. This is one of the reasons why the MOC pastes have high strength retention in the raw brine and aging brine. The other is the addition of anti-corrosion admixture brings about $30 \%$ higher strength retention in $\mathrm{H} 10$ than P1 when compared to the P1 samples. As compared to Figure $3 a$ and $b$, we can clearly find that the strength retentions for the immersing in the raw brine are all higher than the aging brine for the same immersion time. The reason for this phenomenon may be that

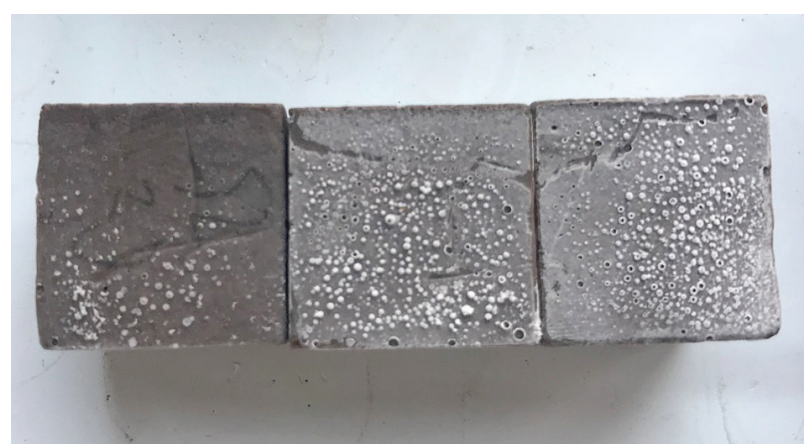

Figure 4. The MOC samples after being immersed in the raw brine.

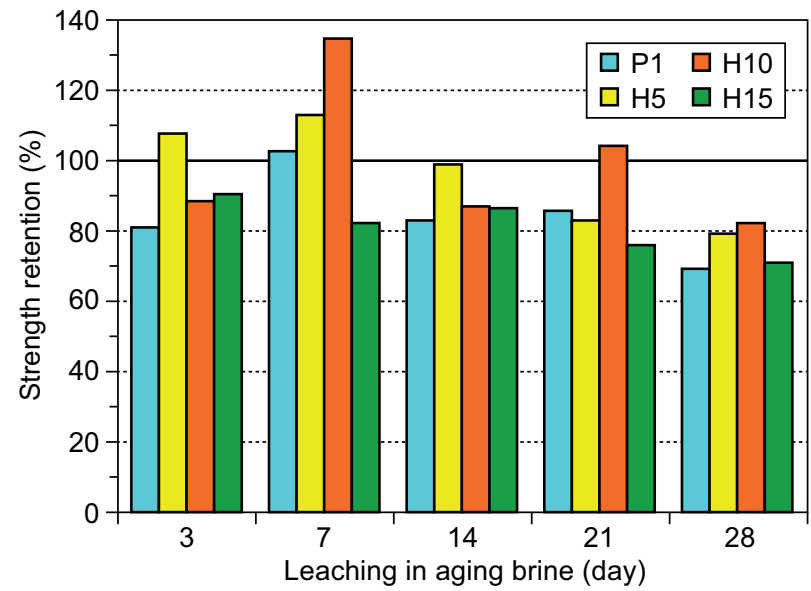

b)

Figure 3. The compressive strength retention of the MOC pastes in the raw brine and aging brine for the different leaching time. 
the raw brine has a higher content of $\mathrm{K}^{+}$than the aging brine, which fills the pores and surface of the MOC to some extent. The salt fills the pores and the surface may prevent entrance of water that leads to the high strength retention. As shown in Figure 4, the samples of the MOC are covered with salt after immersion in the raw brine.

$$
\begin{aligned}
& 5 \mathrm{Mg}(\mathrm{OH})_{2} \cdot \mathrm{MgCl}_{2} \cdot 8 \mathrm{H}_{2} \mathrm{O}= \\
& =5 \mathrm{Mg}(\mathrm{OH})_{2}+\mathrm{Mg}^{2+}+2 \mathrm{Cl}^{-}+8 \mathrm{H}_{2} \mathrm{O} \\
& 3 \mathrm{Mg}(\mathrm{OH})_{2} \cdot \mathrm{MgCl}_{2} \cdot 8 \mathrm{H}_{2} \mathrm{O}= \\
& =3 \mathrm{Mg}(\mathrm{OH})_{2}+\mathrm{Mg}^{2+}+2 \mathrm{Cl}^{-}+8 \mathrm{H}_{2} \mathrm{O}
\end{aligned}
$$

\section{XRD analysis}

The XRD patterns of the MOC after air curing for 28-days are plotted in Figure 5A. From Figure 5A, the main strength phase of MOC was found, which was the $5 \cdot 1 \cdot 8$ crystalline phase. The phase composition of the MOC includes the $5 \cdot 1 \cdot 8$ phase, $\mathrm{MgO}, \mathrm{MgCO}_{3}, \mathrm{Mg}(\mathrm{OH})_{2}$, $\mathrm{CaCO}_{3}$ and $\mathrm{SiO}_{2}$. Among them, $\mathrm{CaCO}_{3}, \mathrm{MgCO}_{3}$ and $\mathrm{SiO}_{2}$ come from uncalcined magnesite. In addition, it can be seen that the peak area of the main strength $5 \cdot 1 \cdot 8$ phase of the MOC specimens without the admixture and with admixture at the different dosages is large, which proves that the content of $5 \cdot 1 \cdot 8$ phase is high and there is little difference between them, so the compressive strength of the specimens is relatively high and is able to maintain above $100 \mathrm{MPa}$. But from the interval graphs Figure $5 \mathrm{Ab}$ and c, after the addition of Q101 and with an increased content of Q101, the content of the $5 \cdot 1 \cdot 8$ phase and the unreacted $\mathrm{MgO}$ decrease. This is due to the addition of Q101 that replaced the $\mathrm{MgO}$ and then decreased the formation of main hydration product. This slight difference in the content of the $5 \cdot 1 \cdot 8$ phase and $\mathrm{MgO}$ is in good accordance with the strength development of the MOC for the 28-day air curing.

The XRD patterns of the MOC after raw brine immersion for 28-days are shown in Figure 5B. It can be seen that the main strength phase is still the $5 \cdot 1 \cdot 8$ phase. Meanwhile, the peak area of brucite is small after the raw brine immersion. This indicates high strength retention for the MOC after the raw brine immersion. In Figures $5 \mathrm{Bb}$ and $\mathrm{c}$, it is interesting to find that the H10 sample has the lowest peak for the $5 \cdot 1 \cdot 8$ phase and $\mathrm{MgO}$. Thus, we can conclude that $\mathrm{H} 10$ has the lowest compressive strength and compressive strength retention after the raw brine immersion from the XRD patterns. However, the fact is that H10 has the highest compressive strength and compressive strength retention after the 28-day raw brine immersion. This strange phenomenon may be due to the salt in the raw brine that fills the surface and pores in H10, which, thus, results in the highest strength and strength retention and the lower content of the $5 \cdot 1 \cdot 8$ phase than the other three samples.

The XRD patterns of the aging brine immersion for the MOC after 28-days are presented in Figure 5C.

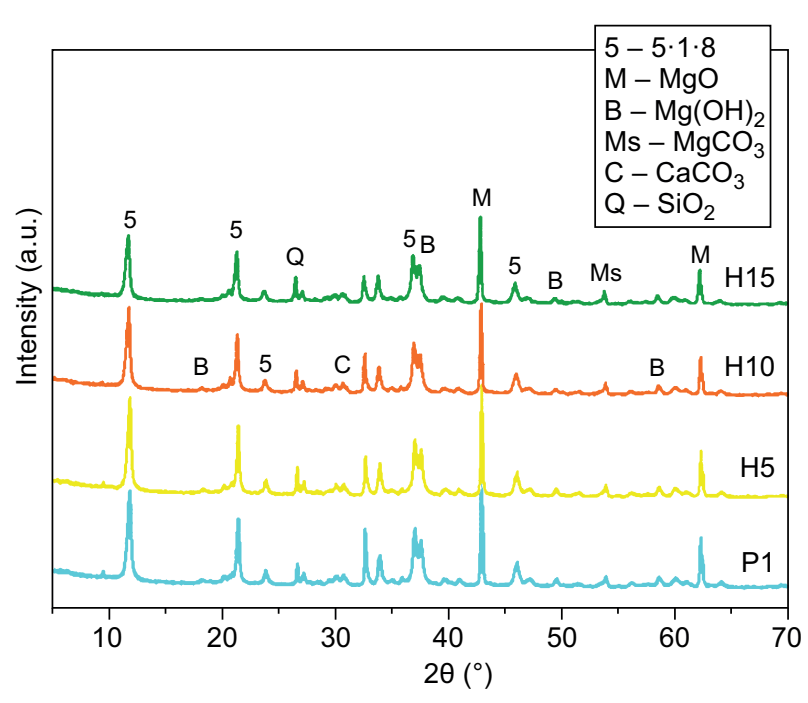

a) XRD patterns

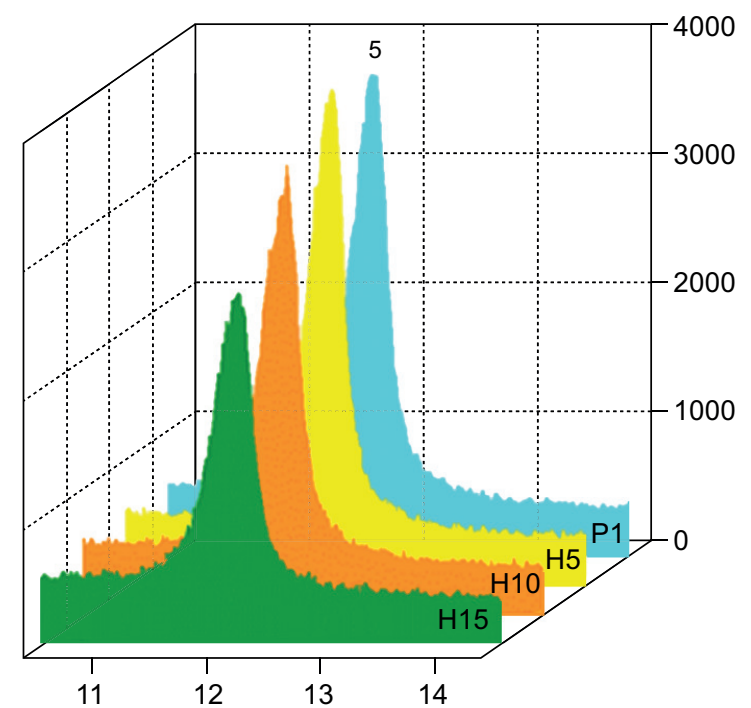

b) interval graph

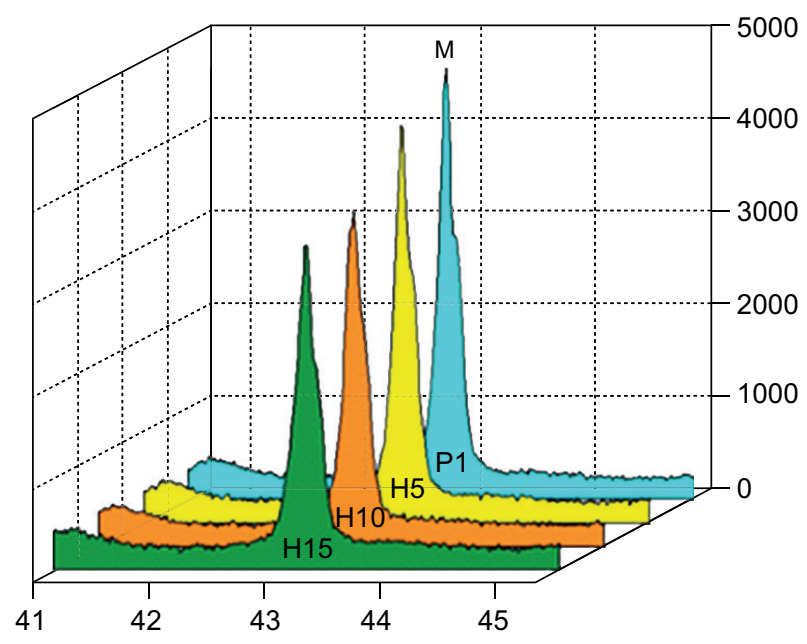

c) interval graph

Figure 5A. The XRD patterns of the MOC pastes cured in air for 28 days. 


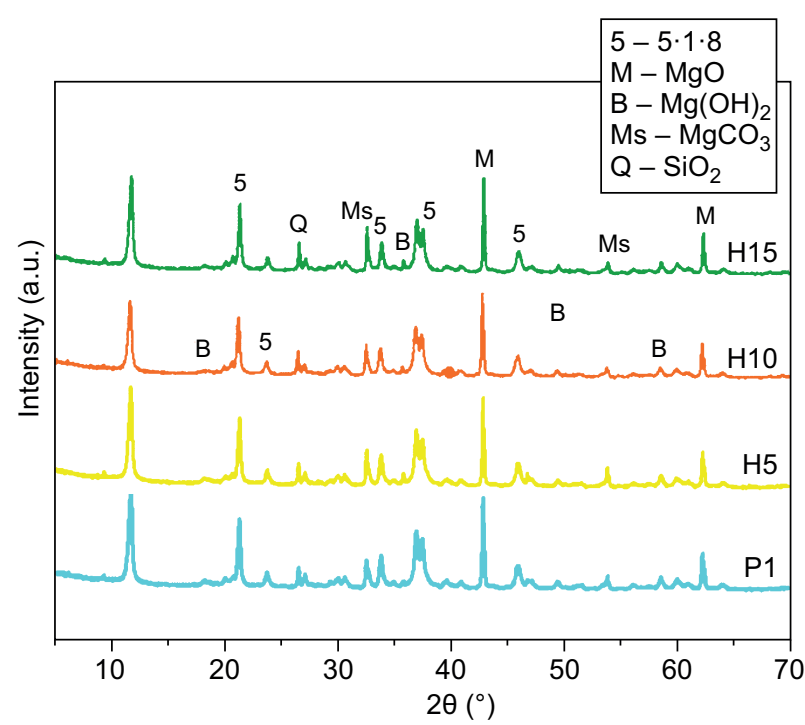

a) XRD patterns

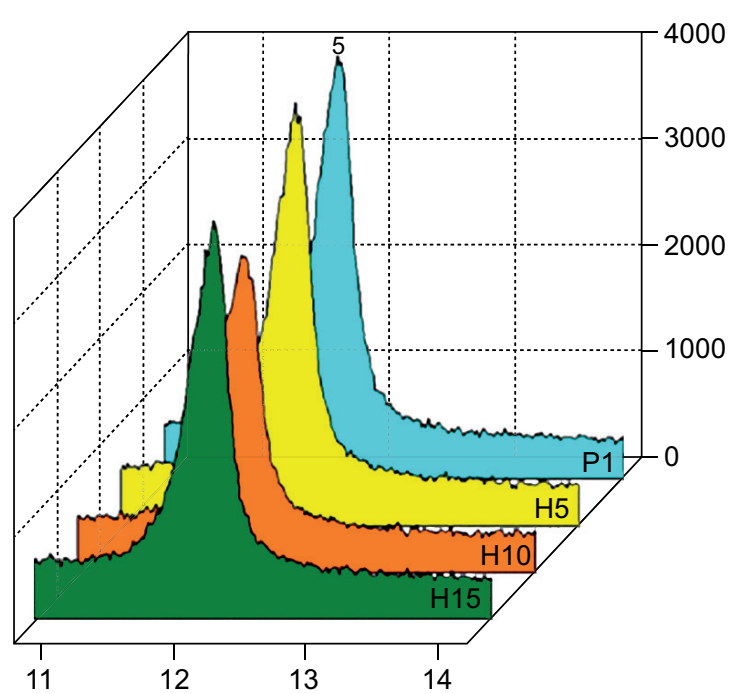

b) interval graph

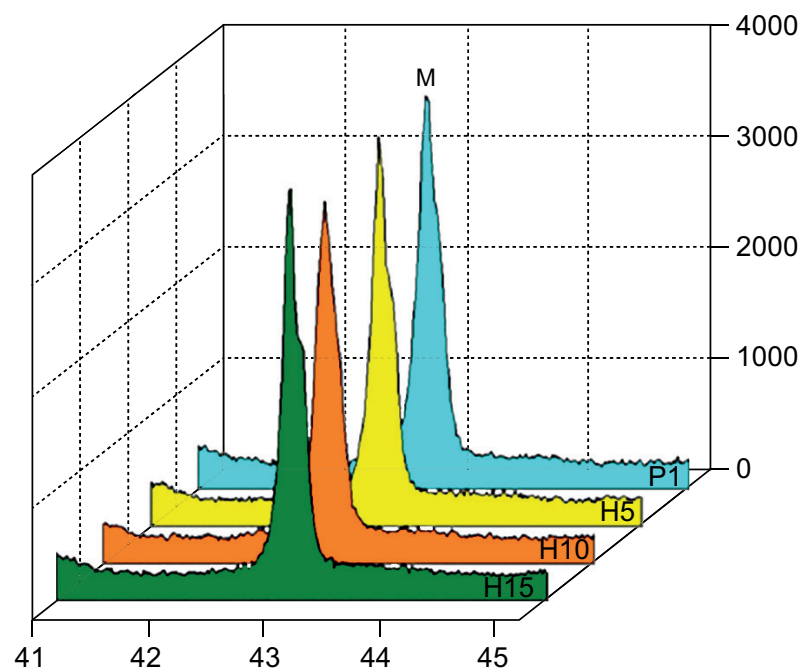

c) interval graph

Figure 5B. The XRD patterns of the MOC pastes immersed in the raw brine for 28 days.

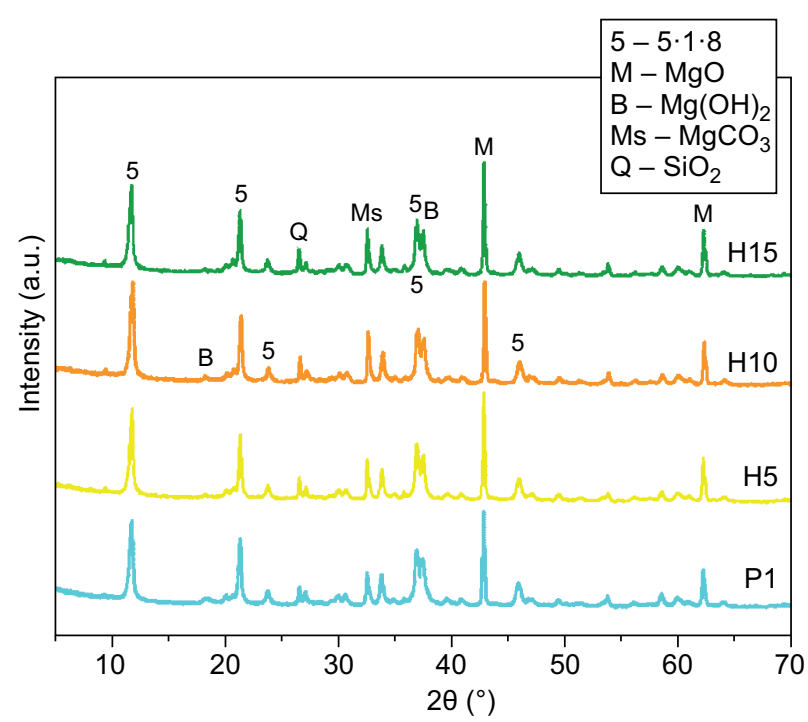

a) XRD patterns

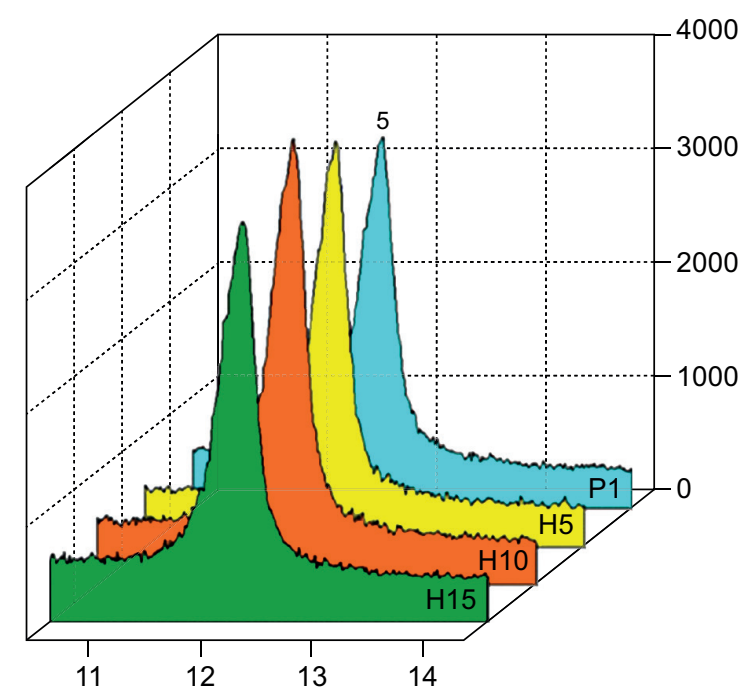

b) interval graph

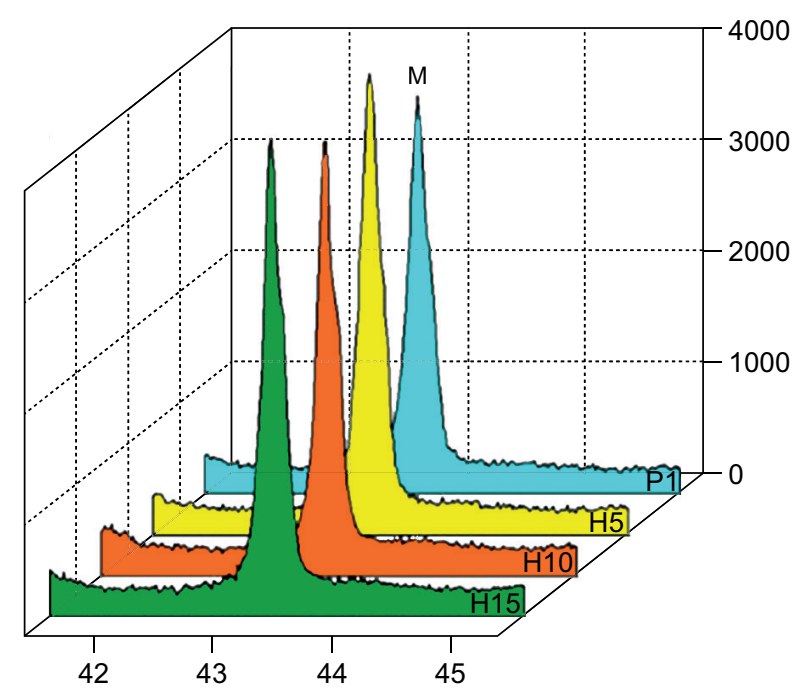

c) interval graph

Figure 5C. The XRD patterns of the MOC pastes immersed in the aging brine for 28 days. 
The main phases after the aging brine are still the $5 \cdot 1 \cdot 8$ phase and the unreacted $\mathrm{MgO}$. This contributes to the high compressive strength and compressive strength retention for the MOC above $80 \mathrm{MPa}$. From the interval graphs (b and c), we can find that $\mathrm{H} 10$ has the highest $5 \cdot 1 \cdot 8$ phase peak area and the lowest $\mathrm{MgO}$ peak area. The XRD results indicate the highest compressive strength and strength retention after 28-days in the aging brine immersion. This is in good consistency with the strength development of the H10 sample.

\section{Microstructure}

Figure 6 shows the electron microscopic image of the MOC specimens with the different ratios of additives cured in the air, immersed in the raw brine and the aging brine for 28 days. In Figure 6a, it can be seen from the 100 times images that the leaf-like matrix appears on the surface of the specimens after the addition of the additive, and the compactness of the surface decreases. With the increase in the amount of the additive, the surface becomes more porous. From the 2000 times images, it can be seen that the main crystalline phase of the MOC specimens with the additive changes from a large number of cementitious and needle-like crystals to partial cementitious crystals. It can be concluded that the addition of the additive has an effect on the micromorphology of the MOC specimens, making the surface of the specimens become a looser structure, which is consistent with the strength retention of the MOC specimens cured in air for 28 days seen in Figure 4.

In Figure 6b, it can be seen from the 100 times images that the surface of the matrix is loose and many voids appear after being soaked in the raw brine for $\mathrm{H} 5$. It can be seen that the surface of the matrix is loose when $5 \%$ of the admixture Q101 is added, but when the content is $10 \%$ and $15 \%$, the surface of the matrix is denser, and when the content is $10 \%$, the surface of the matrix is the densest. From the 2000 times images, the surface of the substrate of the MOC specimen without Q101 is covered with a floc layer. The Energy Dispersive Spectrometer (EDS) proves that it is $\mathrm{Mg}(\mathrm{OH})_{2}$. The

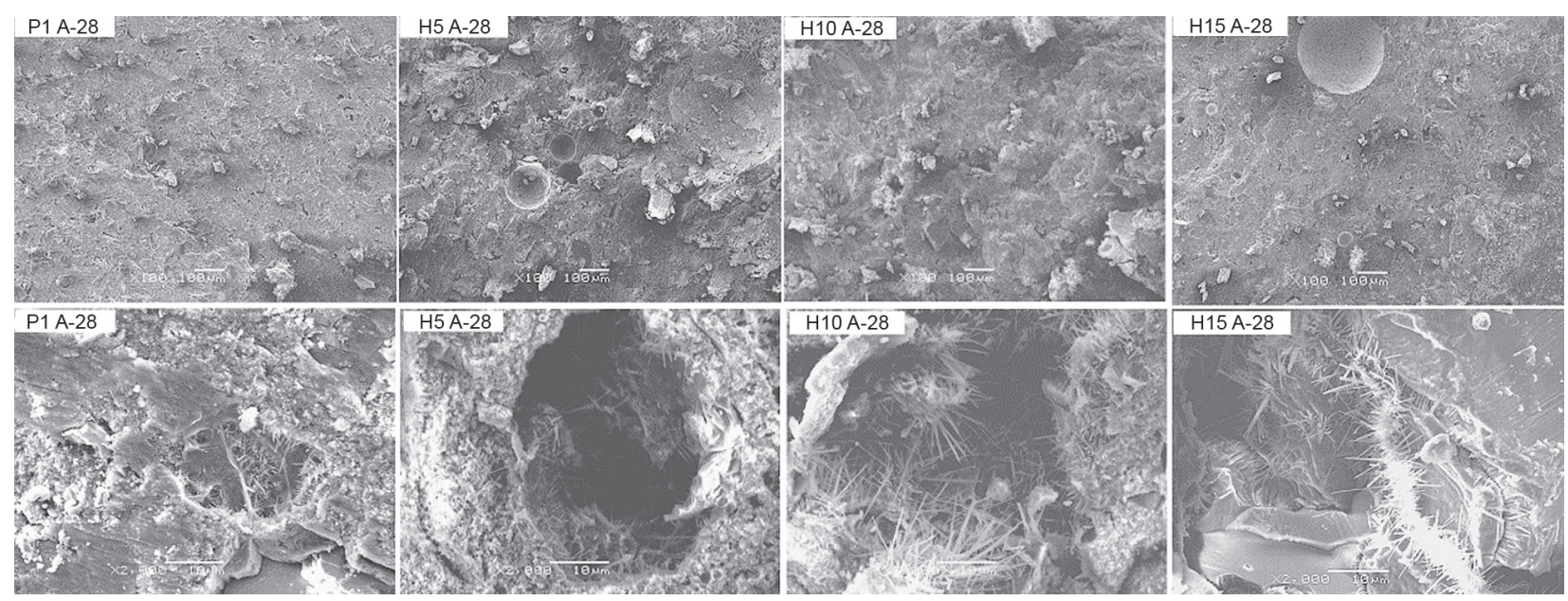

a) air curing for 28 days

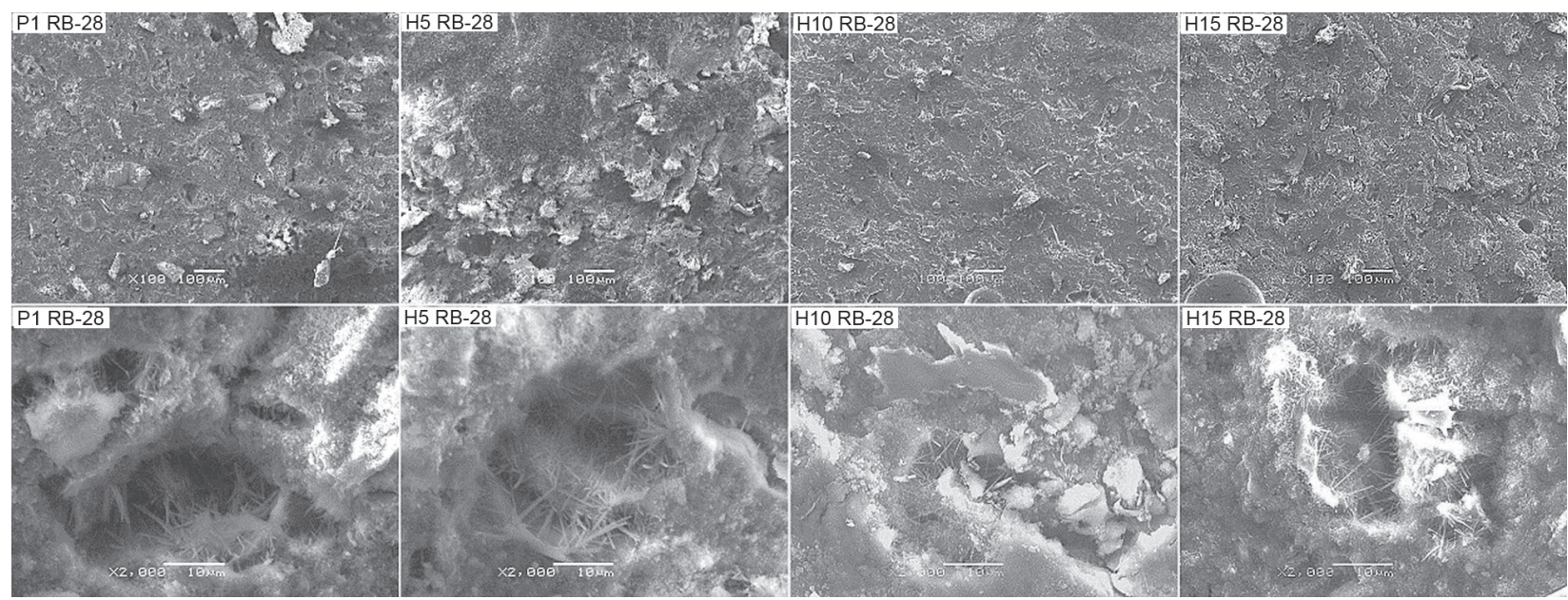

b) immersion in the raw brine for 28 days

Figure 6. The SEM images of the MOC pastes cured in air, immersed in the raw brine and the aging brine for 28 days. (Continue on next page)

Ceramics - Silikáty 63 (4) 347-355 (2019) 
Huang Q., Li Y., Chang Ch., Zheng W., Wen J., Dong J., Man Y., Danchun A., Xiao X., Zhou Y.

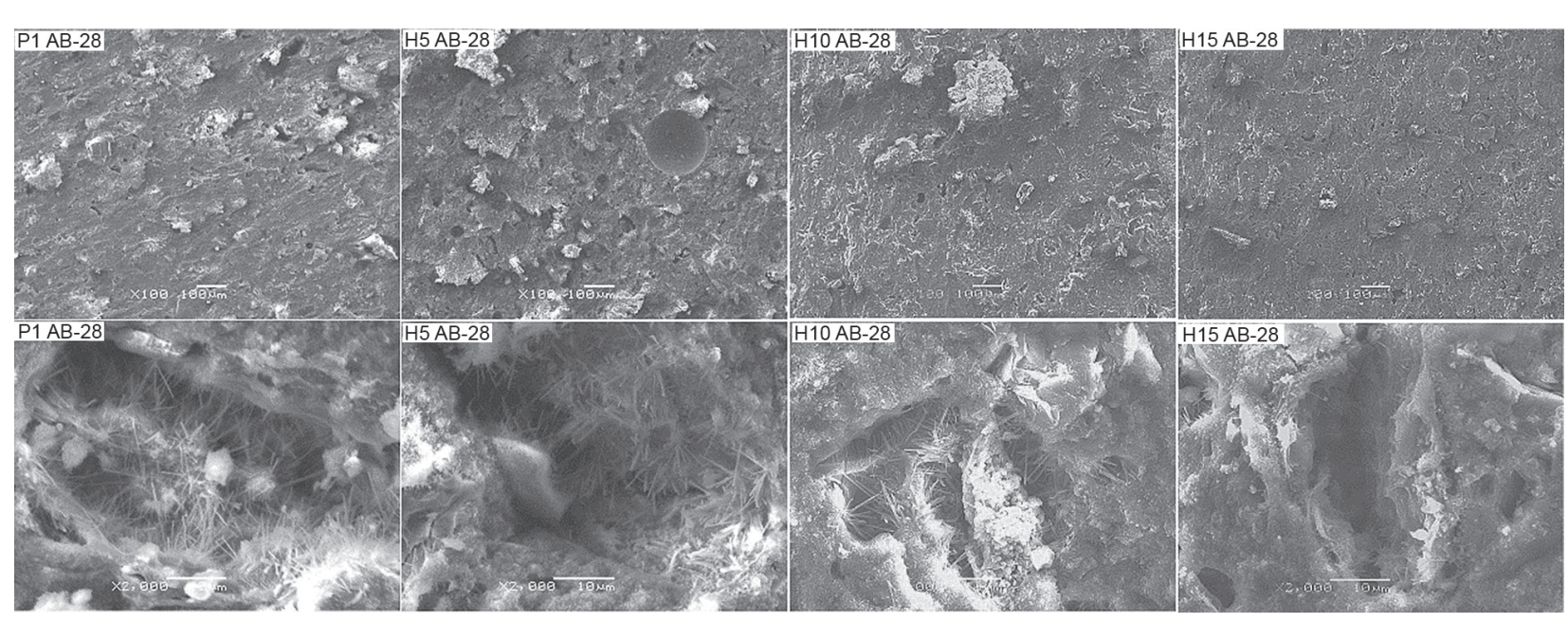

c) immersion in the aging brine for 28 days

Figure 6. The SEM images of the MOC pastes cured in air, immersed in the raw brine and the aging brine for 28 days.

needle-rod crystals and flocs interweave together in the surface. With the addition of the additive, there are a certain amount of leaf-like crystals and gelatins on the surface of the substrate. The leaf-like crystals, needlelike crystals, gelatins and flocs interweave with each other. What is more, with the increase in the amount of the additive, the residual gelatinous and leaf-like crystals on the surface of the substrate increase. When the additive is $10 \%$, the surface of the substrate has the most leaf-like crystals. This confirms that the strength of the MOC specimens with the different dosages of the additive changes differently after being immersed in the raw brine. The larger the amount of the additive, the less obvious the strength reduction is and the larger the strength retention is. In addition, when the additive is $10 \%$, the surface of the matrix is the densest and has the most amount of flaky crystals, and then the strength retention is the highest. It is further confirmed that the optimum dosage of the admixture is $10 \%$ in this experiment.

In Figure 5c, the change rule of the matrix micromorphology is similar to that in Figure 5b, which also confirms that the $10 \%$ admixture is the best optimum dosage in this experiment. But, in Figure 5c, the porosity on the surface of the matrix is obviously more than that in Figure 5b, which proves that the compressive strength and the strength retention of the MOC samples soaked in the raw brine are higher than those soaked in the aging brine in turn.

\section{CONCLUSION}

This work investigates the performance of magnesium oxychloride cement in a brine environment after the addition of an anti-corrosion admixture. A series of tests on the compressive strength, strength retention, mineralogical composition and microstructure of the MOC have been carried out. Based on the experimental results, the conclusions can be drawn as follows:

- The compressive strength of the MOC with the Q101 admixture maintains high strength, more than $100 \mathrm{MPa}$ in air, and decreases slightly in the raw brine and ageing brine, but the decreases are not significant with $80 \mathrm{MPa}$ compressive strength. This indicates the excellent salt brine resistance of the MOC.

- The compressive strength and strength retention of the MOC after the raw brine immersion are higher than the aging brine immersion. The reason may be that the salt fills the surface and the pores in the samples that prevent water erosion to some extent.

- The development of the compressive strength and strength retention demonstrated that the optimum dosage of Q101 is $10 \%$ in the brine environment over the long run.

- The phase composition proves that the addition of Q101 affects the content of the phase rather than the phase composition.

- The addition of Q101 makes the micro-morphology of the MOC transform a large number of cementitious crystals and a small number of acicular crystals into partial cementitious crystals, acicular rod crystals and leaf-like crystals, which maintain its strength in the brine environment.

\section{Acknowledgements}

Funding: Financial support from the Special Major Project for the Transformation of Scientific and Technological Achievements of Qinghai Province (grant numbers 2018-NN-152 and 2019-GX-165), the Major Project for the Science and Technology Development of Qinghai Province, (grant numbers 2015-GX-A1A and 2014-GX$A 2 A)$, the Natural Science Founda-tion of China (grant number U1507120) and the Youth Innovation Promotion Association CAS (grant numbers 2018467 and 2019423) is gratefully acknowledged. 


\section{REFERENCES}

1. Xiao X., Chang C., Zheng W., et al. (2016): Study on mechanical properties of magnesium oxychloride cement concrete pavement. Journal of Salt Lake Research, 3, 50-54.

2. Li Y., Yu H., Dong J., Tan Y. (2013): Research development on hydration product, phase transformation and water resistance evaluation method of magnesium oxychloride cement. Journal of the Chinese Ceramic Society, 41(11), 1465-1473. Doi: 10.7521/j.issn.0454-5648.2013.11.02

3. Zhou M., Gong Y., Qi Z. (2005): The experimental research on the magnesium oxychloride cement product modified by fly ash. Fly Ash Comprehensive Utilization, 5, 29-31.

4. Zhang C., Yang H., Ma X. (2014): Research progress of magnesium oxychloride cement. Bulletin of the Chinese Ceramic Society, 33(1), 117-121.

5. Wen J., Yu H., Wu C., et al (2013): Hydration kinetic and influencing parameters in hydration process of magnesium oxychloride cement. Bulletin of the Chinese Ceramic Society, 41(5), 588-596.

6. Dong R., Wang M., Zhang Q., et al. (2011): Measurement for the free calcium oxide in dolomine half roasting product. Journal of Salt Lake Research, 19(2), 25-28.

7. Zeng X. (2014): Research progress of magnesium oxychloride cement. Guangdong Building Materials, 4, 21-23.

8. Jin Y., Xiao L., Zhao Y. (2000): Effect of additives on water resistance of magnesium oxychloride cement. Jilin Building Materials, 2, 11-13.

9. Chua C., Chan J., Li Z. (2009): Influences of fly ash on magnesium oxychloride mortar. Cement and Concrete Composite, 31(4), 250-254. Doi: 10.1016/j.cemconcomp. 2009.02.011

10. Li Z., Chua C. (2007): Influence of molar ratios on properties of magnesium oxychloride cement. Cement and Concrete Research, 37(6): 866-870. Doi: 10.1016/j.cemconres.2007.03.015
11. Shivrly R. (1916): An investigation of composition flooring. The Journal of Industrial and Engineering Chemistry, 8(8), 679-682.

12. Yu H. (2004). Study on high performance concrete in salt lake: Durability, mechanism and service life prediction. Southeast University, Nanjing.

13. Tu P. (2009). Technology and application of magnesium oxychloride material. Chemical Industry Press, Beijing.

14. Wu D., Liu Q., Yu H., et al. (2014) : Experimental study on strength development of different proportions of magnesium oxychloride cement in brine. Concrete, 4, 24-27.

15. Deng D. (2005). A study on the therories and techniques for improving the properties of $\mathrm{MgO}$-based basic salt cements and their articles. Central South University, HuNan.

16. Sorrention B M, Barret P. (1986). Investigation on the system $\mathrm{MgO}-\mathrm{MgCl}_{2}-\mathrm{H}_{2} \mathrm{O}$ and hydration of Sorel cement. In: 7th In Congregant on the Chemical of Cement, 3.

17. Zhang C., Deng D. (1994): Stability of the reaction products of magnesium oxychloride cement in water. Wuhan University Technology, 9 (3), 51-59.

18. Li Y., Yu H., Dong J., et al. (2010): Research progress in deliquescence dehalogenation and efflorescence of magnesium oxychloride cement. Bulletin of the Chinese Ceramic Society, 29(4), 858-865.

19. Huang Q., Xiao X.Y., Li Y., et al. (2018): Research on the properties of magnesium oxychloride cement prepared with simulated seawater. Advances in Cement Research, 30(7), 277-284. Doi: 10.1680/jadcr.17.00127

20. Huang Q., Li Y., Zheng W.X., et al. (2019): Investigation on the properties of magnesium oxychloride cement prepared by seawater. Advances in Cement Research, Article in press. Doi:10.1680/jadcr.18.00159

21. Deng D. (2003): The mechanism for soluble phosphates to improve the water resistance of magnesium oxychloride cement. Cement and Concrete Research, 33 (9), 1311-1317. Doi: 10.1016/S0008-8846(03)00043-7 